\title{
불면증의 인지행동치료
}

이 은

연세대학교 의과대학 정신과학교실

\section{Cognitive behavior therapy for insomnia}

\section{Eun Lee, MD}

Department of Psychiatry, Yonsei University College of Medicine, Seoul, Korea

Sleep disturbances, including not being able to fall asleep easily/difficulty falling asleep, waking up frequently, or waking up too early and being unable to fall asleep again/resume sleep are diagnosed as insomnia if they cause significant disruption to daily life and are not caused by other sleep disorders such as pain or sleep apnea. Although insomnia is not considered a serious life-threatening condition, it has not only a high prevalence rate but also a high recurrence rate and tends to become chronic. Chronic insomnia patients tend to show common behavioral and cognitive patterns, typical of which are worrying about not being able to fall or stay asleep, excessive awakening because of this worry, limiting and reducing daytime activities or attempting to stay in bed for long periods to compensate for lack of sleep. These cognitive and behavioral characteristics are important contributing factors for the continuation of insomnia. To date, the most popular and effective treatment option/approach recommended by experts for insomnia is cognitive behavior therapy (CBT). CBT for insomnia consists of the following three non-pharmaceutical treatment elements: 1) behavioral elements such as stimulus control therapy, sleep restriction therapy, and muscle relaxation, 2) cognitive elements, and 3) educational elements focusing on sleep hygiene. However, there are barriers to insomnia patients receiving this treatment including accessibility and cost, despite the abundance of evidence demonstrating their effectiveness. Recently, online CBT for insomnia has become available as an alternative, and its emergence is providing a solution to the barriers to access.

Key Words: Sleep initiation and maintenance disorders; Sleep wake disorders; Cognitive behavior therapy

서론

불면증은 수면의 양이나 질에 대한 어려움이 최소 3개월 동안 일주일에 3일 이상 발생하며 이로 인하여 임상적으로

Received: August 15, 2020 Accepted: August 19, 2020

Corresponding author: Eun Lee E-mail: leeeun@yuhs.ac

\section{(C) Korean Medical Association}

This is an Open Access article distributed under the terms of the Creative Commons Attribution Non-Commercial License (http://creativecommons. org/licenses/by-nc/3.0) which permits unrestricted non-commercial use, distribution, and reproduction in any medium, provided the original work is properly cited.
유의미한 수준의 고통이나 학업, 직업 등 중요한 영역에서의 기능손실이 수반되는 경우 진단할 수 있다. 수면에 대한 어려 움은 잠을 시작하거나 유지하는 데 어려움이 있거나 적절한 기회에도 불구하고 다시 잠을 이룰 수 없는 새벽각성이 대표 적인 증상이다. 이러한 문제가 수면무호흡과 같은 다른 수면 장애에 의해 발생한 경우는 진단하지 않는다. 하지만, 다른 정신질환이나 신체질환을 동반하는 경우는 진단할 수도 있 다. 2013년에 개정된 제3판 국제수면장애분류(International Classification of Sleep Disorders, ICSD-3)와 제5판 정신질 환 진단 및 통계 매뉴얼(Diagnostic and Statistical Manual of Mental Disorders, DSM-5) 모두 이전에 사용하던 일차 
성 불면증(primary insomnia)이라는 명칭과 진단기준 대신 불면장애(insomnia disorder)라는 개념을 도입하였다[1,2]. 이전 진단명이었던 일차성 불면증은 다른 정신질환이나 내과 적 질환 등 불면의 원인이 될 만한 다른 요인이 없어야만 진 단이 가능했다. 하지만 ICSD-3와 DSM-5의 불면장애는 다 른 질환이 동반되더라도 그 질환이 불면 증상을 충분히 설명 하지 못하는 경우라면 진단이 가능하다.

불면증은 매우 흔한 질환일 뿐만 아니라 나날이 증가하는 추세이기도 하다. 유병률은 전 세계적으로 적어도 $10 \%$ 이 상으로 추정되는데 진단에 사용한 도구의 특성에 따라 그 차이가 큰 편이다[3]. 불면증 환자의 45-75\%는 만성 환자 이며[2], 회복 후 재발률이 상대적으로 높다고 알려져 있다 (12-33\%)[3]. 불면증 환자의 증가 추세는 세계적인 흐름이 며 우리 나라도 마찬가지다[4,5]. 건강보험공단의 청구 통계 자료에 따르면 2012년부터 2016년 사이 우리나라 수면장애 환자수는 $34 \%$ 증가하였다[6]. 최근에 공개된 또 다른 보험 공단의 자료도 2015년으로부터 2019년 사이 우리나라 불면 증 환자수는 4년만에 $29 \%$, 진료비는 $65 \%$ 증가하였다고 보 고하고 있다[7].

불면증은 단기적으로는 집중력을 떨어뜨리거나 기분조절 을 어렵게 하여 낮 동안의 학업이나 업무능력의 저하를 일으 킬 수 있다. 장기적으로는 정신 및 신체 질환에 이환될 위험 을 높이는 것으로 알려져 있다[8]. 만성 불면증으로 지속될 경우 우울증이나 치매와 같은 정신질환의 발병의 위험을 증 가시킨다는 보고 $[9,10]$ 와 당뇨 및 심혈관계질환의 발생 혹 은 악화의 위험을 높여 결국 사망률의 증가에 기여한다는 연 구보고들은 불면증을 결코 가볍게 여길 수 없음을 보여준다 [11-13]. 또한, 불면증이 생명을 위협하는 심각한 질병은 아 니지만 만성화되고 재발하는 경향으로 인해 불면증으로 인 한 사회경제적 비용은 상당한 편이다. 아직까지 우리나라 연 구결과는 없지만, 미국과 캐나다의 연구결과를 보면 불면증 으로 인한 사회경제적 손실의 규모를 미루어 짐작할 수 있 다. 2011년 미국의 연구자들은 매년 불면증으로 인한 미국 의 경제적 손해의 규모가 매년 632 억 달러라는 계산을 하였 고, 2009년 캐나다 퀘벡 지역만을 대상으로 실시된 불면증 으로 인한 경제적 손실규모 추산 연구에서는 불면증으로 인
한 직간접 비용손실이 1 인당 매년 3,800 달러 수준이라고 보 고하였다[14,15].

불면증 전문가들이 최우선적으로 권하는 불면증에 대한 치료방법은 불면증 인지행동치료이다. 전 세계의 불면증 치 료 가이드라인은 모두 불면증 인지행동치료를 일차 선택 치 료로 추천한다[16,17]. 불면증 인지행동치료)가 불면증의 일 차 치료법이 된 지는 벌써 30 년이 지났다. 이 지면에서는 불 면증 인지행동치료가 무엇인지, 그리고 한계점, 대안은 어떤 것이 있는지에 대해 논의하겠다.

\section{불면증의 원인}

불면증의 원인에 대해서는 통합적인 모델로 설명하는 Spielman [18]의 3P 모델이 가장 널리 받아들여지고 있다. Spielman은 불면증의 원인을 포괄적인 관점에서 선행 요인 (predisposing factor), 유발 요인(precipitating factor), 지 속 요인(perpetuating factor)으로 설명한다. 또한, 이 모델 은 불면증의 비약물학적 치료가 왜 효과적인지 개념을 이해 하는 데에 도움이 된다. $3 \mathrm{P}$ 모델은 만성 불면증의 메커니즘 을 볼 때, 질병 발생 전에 가지게 되는 기질이 불면증 발생 에 취약한 요인으로 작용하게 된다는 의미에서 선행요인의 개념을 설명한다. 선행요인은 생물심리사회적 전 영역에 걸 쳐 존재한다. 생물학적 선행요인으로는 과다각성/민감반응 성(hyperarousal/hypersensitivity) 또는 타고난 수면 발생 기전의 취약성이 있다. 심리적 선행요인으로는 지나치게 걱 정이 많은 성향이 있고, 사회적 선행요인으로는 함께 잠을 자는 사람과 수면주기가 맞지 않거나 주야간 교대근무를 하 는 경우 등이 있다. 유발요인은 환자의 선행요인과 상호작용 하여 일시적으로 수면 개시 또는 유지 문제를 초래하는 요인 을 의미한다. 질병으로 인한 입원이나 이로 인한 스트레스, 직장이나 학업 생활의 어려움, 시험, 이혼, 사별과 같은 대 인관계의 문제 등은 수면에 부정적인 영향을 미치며 불면증 의 급성 단계에 작용하는 유발요인의 흔한 예이다. 불면증이 지속되면 지속될수록 좋은 수면에는 해로운 불순응적인 행 동과 부정적 인지가 증가하여 결과적으로 수면에 대한 스트 
레스를 증가시켜 더욱 심한 과다각성을 일으켜 불면의 악순 환을 야기한다. 잠을 잘 수 있을지에 대한 걱정, 걱정을 되새 기기, 불면증에 대한 과도하고 재앙화 하는 생각, 더 자기 위 해 침대에 오래 누워 있거나 낮잠을 더 많이 자려는 행동, 불 규칙한 수면 스케줄, 잠을 잘 때 외에도 침대에서 생활하는 습관, 음주습관이나 수면제 복용, 카페인 음료 마시기 등이 불면증의 지속요인으로 작용하는 불순응적 행동과 부정적 인지의 대표적인 예이다. 이러한 불순응적 행동, 역기능적 사고(dysfunctional thought), 인지적 과다각성(cognitive hyperarousal)은 모두 불면증의 만성화에 기여한다. 불면증 인지행동치료는 불면증의 원인 중 지속요인을 교정하는 데 에 그 목적이 있으며 치료를 통해 일주기 리듬과 수면의 항 상성을 회복하는 데에 영향을 주고자 하는 것이다.

\section{불면증의 비약물적 치료: 불면증 인지행동치료}

불면증 인지행동치료는 1) 자극조절요법(stimulus control therapy), 수면제한요법(sleep restriction therapy), 근육이 완으로 구성된 행동요소, 2) 인지요소, 3) 수면위생을 중심으 로 한 교육적 요소 등 불면증에 대한 다양한 종류의 비약물 적 치료요소를 함께 제공하는 것이다. 불면증 인지행동치료 를 구성하는 요소들 중 행동요소에는 불면증에 대한 자극조 절요법, 수면제한요법, 근육이완요법 등이 대표적인 비약물 적 치료요소이며 인지요소는 우울증의 인지행동치료와 비슷 하다. 수면위생은 수면에 대한 상식이나 일반적인 행동원칙 을 교육하는 내용이다.

불면증에 대한 자극조절요법은 불면증 인지행동치료 중 치 료의 효과가 큰 행동요법의 일종이다[18]. 자극조절요법은 수 면과 관련된 학습이론에 근거한 것으로, 잠들기 어렵게 만드 는 외부적 또는 심리적 요인이 자극으로 작용한다고 전제한 다. 만성적인 불면증 환자들에게 침실 및 침대 주변환경은 수 면 시작의 어려움을 강화하는 여러 종류의 괴롭고 두려운 감 정들과 연결되는 자극으로 작용할 수 있다. 즉, 오랫동안 누 워서 잠을 청하였던 행동들은 결과적으로는 수면을 방해하는
행동이며, 이러한 행동들은 잠이 오지 않아 두렵고 괴로운 감 정들과 연관된다. 자극조절요법은 침대와 침실 환경을 수면 을 방해하는 행동과의 연결을 끊어내도록 변화시키고 수면을 강화하는 행동과 연결되는 조건화 자극(conditioned stimuli) 으로 작용하도록 하여 일관성 있는 수면-각성 패턴을 만드는 것이 그 목적이다. 자극조절요법의 구체적 지침의 내용은 다 음과 같다. 첫째, 졸릴 때만 잠을 잔다. 둘째, 잠과 성행위 이 외의 다른 용도로 침대를 사용하지 않는다. 침대에서 책을 읽 거나 텔레비전을 보거나, 밥을 먹거나, 고민하지 말라. 셋째, 잠을 잘 수 없으면 일어나서 다른 방으로 가라. 원하는 만큼 잠을 자고 침실로 돌아가라. 잠들지 않고 10 분 이상 침대에 누워 있지 말라. 넷째, 아직도 잠이 오지 않으면 이전 단계를 반복하라. 다섯째, 아무리 잠을 적게 자더라도 매일 아침 같 은 시간에 일어난다. 이것은 일관된 수면리듬을 확립하는데 도움이 된다. 여섯째, 낮잠을 자지 않는다.

수면제한요법도 자극조절요법과 마찬가지로 행동요법의 일종이며 불면증 인지행동치료의 중요한 치료요소이다[19]. 수면제한요법 이론에 따르면 불면증 환자들이 잠을 자기 위 해 너무 많은 시간을 들이다 보면 깨어 있는 시간이 늘어나 고, 수면이 파편화되며, 자는 시간과 깨어 있는 시간이 불규 칙 해져 점점 더 수면을 예측하기 어려워진다. 누워 있는 시 간을 실제 수면시간에 30 분 정도만 더한 수준으로 제한하고 수면 스케줄을 규칙적으로 고정하는 것이 수면제한요법의 핵심이다. 치료자는 환자가 작성해 온 2 주간의 수면 일지를 바탕으로 누워 있는 시간을 처방한다. 수면시간이 늘어나면 누워 있는 시간도 조금씩 늘려준다.

근육이완요법은 1930 년대 처음 개발되어 불면증 환자들 에게 그 효과가 입증된 불면증의 비약물학적 치료의 효시라 고 할 수 있다[20]. 점진적 이완요법은 근육긴장을 줄여주고 수면에 영향을 주는 여러가지 쓸데없는 생각들을 줄이는 데 에 도움을 주는 것으로 알려졌다[21]. 한편 근육이완요법이 불면증 환자들의 수면 시작의 어려움을 호전시키고 총 수면 시간을 늘린다는 연구보고도 있다[22].

수면위생은 잠을 잘 자기 위해 지켜야 하는 보편 타당한 행동원칙들을 일컫는다. 1977년 Hauri [23]가 처음 주장하 였다. 불면증 환자들에게만 적용되는 원칙은 아니며 좋은 수 
면을 촉진하기 위해 일반적으로 추천되는 내용이며 여러 기 관이나 단체마다 조금씩은 다르다. 우리나라 질병관리본부 홈페이지에 실려 있는 불면증 관련 건강정보 중에도 수면위 생에 대한 내용이 있는데, 그 내용은 다음과 같다[24]. 첫째, 낮잠을 피한다. 밤에 충분히 자지 못하여 낮에 피곤하고 졸 려서 낮잠을 자게 되면 밤에 잠을 못 자게 되는 악순환이 일 어나므로 낮잠을 자지 않는 것이 좋다. 둘째, 잠자리에 누워 있는 시간을 일정하게 한다. 예를 들어 수면시간을 8시간으 로 결정했으면 잠을 잤는지 여부와 관계없이 침대에 눕기 시 작한 순간부터 8시간이 지나면 일어나서 침대를 떠나야 한 다. 셋째, 잠자리에 누워서 10 분 이상 잠이 들지 않으면 일 어나서 침대 밖으로 나와 단순한 작업을 하면서 잠이 올 때 까지 기다린다. 이때 $\mathrm{TV}$ 를 보는 것보다는 책을 읽는 것이 좋 다. 넷째, 침대는 오로지 잠을 자기 위해서만 사용하고 다른 일을 하거나 생각하기 위해 침대에 눕는 것을 피한다. 다섯 째, 주말이나 휴일에도 일어나는 시간을 일정하게 한다. 주 중에 수면이 부족했다고 해서 주말에 늦잠을 자지 않도록 한 다. 여섯째, 밤에 깨더라도 시계를 보지 않는다. 일곱째, 매 일 규칙적으로 운동을 하고 저녁 늦은 시간에는 운동을 하지 않는 것이 좋다. 여덟째, 잠자리에 들기 약 2 시간 전에 따뜻 한 물로 목욕을 하면 잠이 드는 데 도움이 된다. 아홉째, 수 면을 방해하는 담배, 커피, 홍차, 콜라, 술 등을 피한다. 술은 수면을 유도하는 효과가 있지만, 숙면을 방해하여 자주 깨게 하고 깊이 잠들지 못하게 하므로 마시지 않도록 한다. 열째, 배고픈 느낌인 공복감도 잠들기 어려운 원인이 되므로 우유 등을 따뜻하게 데워서 마시면 도움이 된다.

불면증의 인지치료요법은 Beck 등[25]의 우울증 인지요법 을 바탕으로 개발된 것으로, 수면에 대한 비현실적인 기대, 불면증의 원인과 결과에 대한 잘못된 인식, 수면을 개선하 는 행동에 대한 잘못된 믿음 등 수면에 대한 기능장애적 태 도에 초점을 맞춰 인지력을 재구성하는 것이다[26]. 이 치료 법이 소개된 지 몇 년 후, Harvey [27]는 불면증을 지속시키 는 다섯 가지 주요 인지과정, 즉 수면 관련 위협에 대한 걱 정, 선택적 주의와 모니터링, 수면과 낮 동안에 발생하는 문 제에 대한 오해, 수면에 대한 도움이 되지 않는 믿음, 그리고 비생산적인 안전행동들을 다루기 위해 새로운 인지요법을
제안했다. Harvey가 개발한 불면증 인지요법은 치료의 초점 에 낮 동안의 생각과 행동을 포함한다는 점에서 처음 개발된 Morin 등[26]의 인지요법과는 다른 특성이 있다.

이렇게 개발된 비약물적 치료요소들을 묶어서 제공하는 불면증 인지행동치료에 대한 효과에 대한 메타분석 결과는 1994년에 처음 출판되었다[26]. 치료는 보통 4주에서 8주 정도 이루어지지만 16 주 동안 시행하는 경우도 있다. 치료 자와 개별적으로, 또는 그룹으로 진행하였던 연구들을 모아 분석한 결과는 불면증 인지행동치료가 수면 시작의 어려움 (mean effect size=0.88) 및 수면 유지 어려움(mean effect size $=0.65$ )의 호전에 효과적임을 보여주었다. 2000 년대에 출판된 또다른 메타분석 연구에서는 불면증 인지행동치료의 단기적 치료효과가 약물치료에 비해 열등하지 않으며 수면 시작의 어려움에 대해서는 약물치료보다 효과적임을 증명하 였다[28]. 이러한 결과들을 바탕으로 미국수면의학회는 불면 증 인지행동치료가 불면증 치료에 가장 효과적인 치료라고 권고하게 되었고[16], 48개의 임상실험에 대한 체계적인 리 뷰를 발표하였다[29].

불면증 인지행동치료는 앞서 설명한 대로, 다른 원인이 없 는 '일차성 불면증' 외에 다른 신체질환이나 정신질환을 동반 하는 '이차성 불면증'에도 효과적이다. 불면증 인지행동치료 의 효과를 알아본 대상질환으로는 우울증, 외상 후 스트레 스 장애와 같은 정신질환이나 암이나 통증질환에 관련된 불 면증, 비정신과 질환과 관련된 이차성 불면증(통증, 암 등)이 있다. 불면증 인지행동치료는 불면증과 우울증 증상 모두의 개선에 효과적임이 증명되었다[30,31]. 외상 후 스트레스 장 애와 동반된 불면증에 대해서도 불면증 인지행동치료가 수 면효율의 개선, 수면 시작의 어려움 문제 모두에 대해 효과 적임이 증명되었다[32]. 만성통증 환자나 암환자, 인체면역 결핍바이러스 감염 환자들의 불면증에 대해서도 불면증 인 지행동치료가 효과적임이 보고된 바 있다[33-35].

이제까지 언급한 수많은 성공적인 결과로 인해 불면증 인지 행동치료는 모든 가이드라인에서 불면증에 대한 일차 선택치 료로 추천되었다. 하지만 이러한 성공에도 불구하고, 불면증 인지행동치료은 여러 가지 제한점을 갖고 있다. 우선, 불면증 인지행동치료의 효과에 대한 연구는 많지만 그 부작용에 대한 
연구는 아직까지 매우 부족하다. 한 연구에서는 불면증 인지 행동치료가 피로감, 탈진, 과도한 졸림, 에너지 저하, 두통 등 과 같은 부작용이 나타날 수 있다고 보고한 바 있다[36]. 두 번 째로, 대면치료를 기본으로 삼기 때문에 생기는 접근성의 한 계가 있다. 치료자는 환자들의 수면 일기를 점검하고 이를 바 탕으로 수면제한요법이나 자극조절요법 등 피드백을 제공하 며 수면 일정을 개별적으로 처방하기 때문에 치료자의 시간과 노력이 많이 든다. 게다가 잘 훈련된 전문가의 부족은 서론에 서 언급한 것과 같은 많은 환자에게 불면증 인지행동을 시행 하는 데 매우 큰 장벽으로 작용한다. 의료기관 접근성이 낮고 불면증의 유병률이 가장 높은 농촌지역 환자와 노인에게 불 면증 인지행동치료를 제공하는 것은 더욱 어려운 일이다[37].

이러한 한계를 해결하기 위해 연구자들은 인터넷을 통한 불면증 인지행동치료를 제공하는 방법을 개발하게 되었다. 인터넷을 통해 불면증 인지행동치료를 제공할 경우 몇 가지 장점이 있다. 우선, 환자는 시간과 장소의 제약을 받지 않고 치료를 받을 수 있다. 또한, 교통수단을 이용하기 어렵거나 병원에 대한 접근성이 낮은 지역에 거주하는 사람들 역시 치 료를 받을 수 있다. 2000년대 초반, 온라인 불면증 인지행동 치료에 대한 효과검증연구가 처음 보고되었는데, 연구진은 총 수면시간, 총 취침시간, 수면효율이 개선되었다고 보고하 였다[28]. 이후 환자 대조군과의 비교 연구에서도 역시 온라 인 불면증 인지행동치료가 수면효율과 수면 시작 후 깨어 있 는 시간을 감소시켰다고 보고하였다[38]. 온라인 불면증 인 지행동치료를 받은 참가자들에 대한 설문조사 결과, $90 \%$ 이 상의 참가자가 온라인을 통한 치료가 편리하고 이해가 쉽고 유용하다고 응답했다[39]. 온라인 불면증 인지행동치료를 받 은 참가자 1,711 명을 대상으로 한 설문조사 결과 역시, 온라 인 불면증 인지행동치료가 불면 증상은 물론 심리적 웰빙, 수면 관련 삶의 질, 기분, 피로, 업무생산성 등에도 개선효과 를 보였다고 보고하였다[40].

\section{결론}

불면증은 흔한 질병일 뿐 아니라 재발률 역시 높고 만성화
되는 경향이 있다. 생명을 위협하는 심각한 질병이 아님에도 불구하고 질병으로 인한 직간접적 사회비용이 클 뿐만 아니 라 정신질환이나 신체질환에 악영향을 끼칠 수 있다. 불면증 환자들은 공통된 행동 및 인지 양상을 보이는 경향이 있는 데, 그 중 대표적인 것이 잠을 못 자는 것에 대한 걱정, 이 걱 정으로 인한 과도한 각성, 못 잔 것을 보상하기 위해 낮 동안 의 활동을 줄이거나 침대에 오래 누워있으려고 하는 시도 등 이다. 불면증 환자들의 이러한 인지적, 행동적 특성은 불면 증이 지속되는 데 중요한 요인으로 작용한다. 현재까지 전문 가들이 권하는 불면증에 대한 치료방법 중 최우선적인 방법 은 불면증 인지행동치료이다. 불면증 인지행동치료는 1) 자 극조절요법, 수면제한요법, 근육이완으로 구성된 행동요소, 2) 인지요소, 3) 수면위생을 중심으로 한 교육적 요소 등 불 면증에 대한 여러 종류의 비약물적 치료요소로 구성된다. 그 러나 불면증 인지행동치료는 그 효과에 대한 증거가 풍부함 에도 불구하고 접근성이나 비용 등의 장벽이 존재한다. 최근 그 대안으로 온라인으로 제공되는 디지털 불면증 인지행동 치료가 장벽의 해결책으로 떠오르고 있다.

찾아보기말: 불면증; 수면장애; 인지행동치료

\section{ORCID}

Eun Lee, https://orcid.org/0000-0002-7462-0144

\section{Conflict of Interest}

No potential conflict of interest relevant to this article was reported.

\section{References}

1.American Academy of Sleep Medicine. International classification of sleep disorders. 3rd ed. Darien: American Academy of Sleep Medicine; 2014.

2. American Psychiatric Association. Diagnostic and statistical manual of mental disorders. 5th ed. Arlington: American Psychiatric Publishing; 2013.

3. Morin CM, Belanger L, LeBlanc M, Ivers H, Savard J, Espie CA, Merette C, Baillargeon L, Gregoire JP. The natural history of 
insomnia: a population-based 3-year longitudinal study. Arch Intern Med 2009;169:447-453.

4. Cao XL, Wang SB, Zhong BL, Zhang L, Ungvari GS, Ng CH, Li L, Chiu HF, Lok GK, Lu JP, Jia FJ, Xiang YT. The prevalence of insomnia in the general population in China: a meta-analysis. PLoS One 2017;12:e0170772.

5. Kronholm E, Partonen T, Harma M, Hublin C, Lallukka T, Peltonen M, Laatikainen T. Prevalence of insomnia-related symptoms continues to increase in the Finnish working-age population. J Sleep Res 2016;25:454-457.

6. National Health Insurance Service. Sleepless nights “insomnia," the number of patients steadily increases [Internet]. Wonju: National Health Insurance Service; 2018 [cited 2020 Aug 17]. Available from: https://www.nhis.or.kr/bbs7/boards/ B0039/25795.

7. Park JS. Four major smartphone diseases cost 433.4 billion won last year: $47 \%$ increase in 5 years. Medical Today. 2019 Oct 1 [cited 2020 Aug 17]. Available from: http://www.mdtoday.co.kr/ mdtoday/index.html?no=366169.

8. Fortier-Brochu E, Beaulieu-Bonneau S, Ivers H, Morin CM. Insomnia and daytime cognitive performance: a meta-analysis. Sleep Med Rev 2012;16:83-94.

9. de Almondes KM, Costa MV, Malloy-Diniz LF, Diniz BS. Insomnia and risk of dementia in older adults: systematic review and meta-analysis. J Psychiatr Res 2016;77:109-115.

10. Riemann D, Voderholzer U. Primary insomnia: a risk factor to develop depression? J Affect Disord 2003;76:255-259.

11.Jackson CL, Redline S, Emmons KM. Sleep as a potential fundamental contributor to disparities in cardiovascular health. Annu Rev Public Health 2015;36:417-440.

12. Kim TH, Carroll JE, An SK, Seeman TE, Namkoong K, Lee E. Associations between actigraphy-assessed sleep, inflammatory markers, and insulin resistance in the Midlife Development in the United States (MIDUS) study. Sleep Med 2016;27-28:72-79.

13.Cappuccio FP, D'Elia L, Strazzullo P, Miller MA. Sleep duration and all-cause mortality: a systematic review and meta-analysis of prospective studies. Sleep 2010;33:585-592.

14.Kessler RC, Berglund PA, Coulouvrat C, Hajak G, Roth T, Shahly V, Shillington AC, Stephenson JJ, Walsh JK. Insomnia and the performance of US workers: results from the America insomnia survey. Sleep 2011;34:1161-1171.

15.Daley M, Morin CM, LeBlanc M, Gregoire JP, Savard J. The economic burden of insomnia: direct and indirect costs for individuals with insomnia syndrome, insomnia symptoms, and good sleepers. Sleep 2009;32:55-64.

16.Schutte-Rodin S, Broch L, Buysse D, Dorsey C, Sateia M. Clinical guideline for the evaluation and management of chronic insomnia in adults. J Clin Sleep Med 2008;4:487-504.

17.Riemann D, Baglioni C, Bassetti C, Bjorvatn B, Dolenc Groselj L, Ellis JG, Espie CA, Garcia-Borreguero D, Gjerstad M, Goncalves $M$, Hertenstein E, Jansson-Frojmark M, Jennum PJ, Leger D, Nissen C, Parrino L, Paunio T, Pevernagie D, Verbraecken J, Weeß HG, Wichniak A, Zavalko I, Arnardottir
ES, Deleanu OC, Strazisar B, Zoetmulder M, Spiegelhalder $\mathrm{K}$. European guideline for the diagnosis and treatment of insomnia. J Sleep Res 2017;26:675-700.

18. Bootzin RR. Stimulus control treatment for insomnia. Proc Am Psychol Assoc 1972;7:395-396.

19.Spielman AJ, Saskin P, Thorpy MJ. Treatment of chronic insomnia by restriction of time in bed. Sleep 1987;10:45-56.

20.Jacobson E. Progressive muscle relaxation. J Abnorm Psychol 1938;75:18.

21.Blanaru M, Bloch B, Vadas L, Arnon Z, Ziv N, Kremer I, Haimov I. The effects of music relaxation and muscle relaxation techniques on sleep quality and emotional measures among individuals with posttraumatic stress disorder. Ment Illn 2012; 4:e13.

22.Alexandru BV, Robert B, Viorel L, Vasile B. Treating primary insomnia: a comparative study of self-help methods and progressive muscle relaxation. J Cogn Behav Psychother 2009; 9:67-82.

23.Hauri P. Current concepts: the sleep disorders. Kalamazoo: Upjohn Company; 1977.

24. Korea Centers for Disease Control and Prevention. Insomnia [Internet]. Cheongju: Korea Centers for Disease Control and Prevention; 2015 [cited 2020 Aug 13]. Available from: http:// health.cdc.go.kr/health/HealthInfoArea/HealthInfo/View. do?idx $=13800$.

25.Beck AT, Rush AJ, Shaw BF, Emery G. Cognitive therapy of depression. New York: Guilford Press; 1979.

26. Morin CM, Culbert JP, Schwartz SM. Nonpharmacological interventions for insomnia: a meta-analysis of treatment efficacy. Am J Psychiatry 1994;151:1172-1180.

27. Harvey AG. A cognitive theory and therapy for chronic insomnia. J Cogn Psychother 2005;19:41-59.

28.Smith MT, Perlis ML, Park A, Smith MS, Pennington J, Giles DE, Buysse DJ. Comparative meta-analysis of pharmacotherapy and behavior therapy for persistent insomnia. Am J Psychiatry 2002;159:5-11.

29. Morin CM, Bootzin RR, Buysse DJ, Edinger JD, Espie CA, Lichstein KL. Psychological and behavioral treatment of insomnia: update of the recent evidence (1998-2004). Sleep 2006;29:1398-1414.

30. Manber R, Edinger JD, Gress JL, San Pedro-Salcedo MG, Kuo TF, Kalista T. Cognitive behavioral therapy for insomnia enhances depression outcome in patients with comorbid major depressive disorder and insomnia. Sleep 2008;31:489-495.

31. Taylor DJ, Lichstein KL, Weinstock J, Sanford S, Temple JR. A pilot study of cognitive-behavioral therapy of insomnia in people with mild depression. Behav Ther 2007;38:49-57.

32.Swanson LM, Favorite TK, Horin E, Arnedt JT. A combined group treatment for nightmares and insomnia in combat veterans: a pilot study. J Trauma Stress 2009;22:639-642.

33. Currie SR, Wilson KG, Pontefract AJ, deLaplante L. Cognitivebehavioral treatment of insomnia secondary to chronic pain. J Consult Clin Psychol 2000;68:407-416. 
34.Dreher HM. The effect of caffeine reduction on sleep quality and well-being in persons with HIV. J Psychosom Res 2003;54:191-198.

35.Schmitz KH, Holtzman J, Courneya KS, Masse LC, Duval S, Kane R. Controlled physical activity trials in cancer survivors: a systematic review and meta-analysis. Cancer Epidemiol Biomarkers Prev 2005;14:1588-1595.

36. Kyle SD, Morgan K, Spiegelhalder K, Espie CA. No pain, no gain: an exploratory within-subjects mixed-methods evaluation of the patient experience of sleep restriction therapy (SRT) for insomnia. Sleep Med 2011;12:735-747.

37. Weyerer S, Dilling H. Prevalence and treatment of insomnia in the community: results from the Upper Bavarian Field Study. Sleep 1991;14:392-398.

38. Ritterband LM, Thorndike FP, Gonder-Frederick LA, Magee JC, Bailey ET, Saylor DK, Morin CM. Efficacy of an Internetbased behavioral intervention for adults with insomnia. Arch Gen Psychiatry 2009;66:692-698.

39.rin CM, Ritterband LM. Development and perceived utility and impact of an internet intervention for insomnia. E J Appl Psychol 2008;4:32-42.

40.Espie CA, Emsley R, Kyle SD, Gordon C, Drake CL, Siriwardena AN, Cape J, Ong JC, Sheaves B, Foster R, Freeman D, Costa-Font J, Marsden A, Luik AI. Effect of digital cognitive behavioral therapy for insomnia on health, psychological well- being, and sleep-related quality of life: a randomized clinical trial. JAMA Psychiatry 2019;76:21-30.

\section{Peer Reviewers' Commentary}

불면증은 불면장애라는 진단명으로 부를 정도로 그 기전의 독 립성이나 질환 자체의 심각성을 인정받고 있다. 불면장애 환자 는 나날이 증가하고 있고 그에 따라 치료법에 대한 관심도 증 가하고 있다. 불면장애를 해결하기 위하여 약물을 처방하는 경 우가 많으나, 스필만(Spielman)의 3P모델에 따라 불면증의 1차 표준치료는 인지행동치료임을 이 논문은 강조하고 있다. 인지 행동치료는 많은 장점을 가지고 있으나, 우리나라에서의 인식 은 아직 많이 부족한 편이다. 인지적 과다한 각성이 불면증을 만성화시키는 요인이며 이러한 과다한 각성을 줄이는 것이 이 치료법의 핵심이다. 이 논문은 인지행동치료의 행동요법, 인지 요법, 수면위생교육 등에 대하여 상세히 설명하고, 실제 임상 적 용의 여러 한계나 제한점을 설명하고 있다. 이 논문은 불면증 환자를 진료하는 임상 현장에 많은 도움을 줄 것으로 판단된다.

[정리: 편집위원회] 